\title{
Role of fractionated radiotherapy in patients with hemangioma of the cavernous sinus
}

\author{
Sunmin Park, MD, PhD, Sang Min Yoon, MD, PhD, Sumin Lee, MD, \\ Jin-hong Park, MD, PhD, Si Yeol Song, MD, PhD, Sang-wook Lee, MD, PhD, \\ Seung Do Ahn, MD, PhD, Jong Hoon Kim, MD, PhD, Eun Kyung Choi, MD, PhD \\ Department of Radiation Oncology, Asan Medical Center, University of Ulsan College of Medicine, Seoul, Korea
}

\begin{abstract}
Purpose: We performed this retrospective study to investigate the outcomes of patients with hemangioma of the cavernous sinus after fractionated radiotherapy.

Materials and Methods: We analyzed 10 patients with hemangioma of the cavernous sinus who were treated with conventional radiotherapy between January 2000 and December 2016. The median patient age was 54 years (range, 31-65 years), and 8 patients (80.0\%) were female. The mean hemangioma volume was $34.1 \mathrm{~cm}^{3}$ (range, $6.8-83.2 \mathrm{~cm}^{3}$ ), and fractionated radiation was administered to a total dose of 50-54 Gy with a daily dose of $2 \mathrm{~Gy}$.

Results: The median follow-up period was 6.8 years (range, 2.2-8.8 years). At last follow-up, the volume of the tumor had decreased in all patients. The average tumor volume reduction rate from the initial volume was 72.9\% (range, 18.9-95.3\%). All 10 of the cranial neuropathies observed before radiation therapy had improved, with complete symptomatic remission in 9 cases $(90 \%)$ and partial remission in 1 case $(10 \%)$. No new acute neurologic impairments were reported after radiotherapy. One probable compressive optic neuropathy was observed at 1 year after radiotherapy.

Conclusion: Fractionated radiotherapy achieves both symptomatic and radiologic improvements. It is a well-tolerated treatment modality for hemangiomas of the cavernous sinus.
\end{abstract}

Keywords: Hemangioma, Cavernous sinus, Radiotherapy

\section{Introduction}

Hemangiomas are true neoplasms of endothelial cells and should be differentiated from vascular malformations that are localized defects of vascular morphogenesis [1]. Hemangiomas of the cavernous sinus are rare vascular benign tumors that account for less than $3 \%$ of all benign lesions occurring in the cavernous sinus and 2\% of all tumors, both benign and malignant [2-4]. Hemangiomas in the cavernous sinus differ from other intra-axial cavernous malformations in the brain because they produce symptoms that result from progressive tumor growth and a mass effect.

Hemangiomas of the cavernous sinus present considerable therapeutic challenges because of their proximity to important vasculature, cranial nerves, and endocrine tissue at the anterior cranial base. The optimal treatment strategy

Received 17 April 2017, Revised 28 June 2017, Accepted 10 July 2017.

Correspondence: Sang Min Yoon, MD, PhD, Department of Radiation Oncology, Asan Medical Center, University of Ulsan College of Medicine, 88 Olympic-ro 43-gil, Songpa-gu, Seoul 05505, Korea. Tel: +82-2-3010-5615, Fax: +82-2-3010-6950, E-mail:drsmyoon@amc.seoul.kr

(c) This is an Open Access article distributed under the terms of the Creative Commons Attribution Non-Commercial License (http://creativecommons.org/ licenses/by-nc/4.0/) which permits unrestricted non-commercial use, distribution, and reproduction in any medium, provided the original work is properly cited.

www.e-roj.org 
for this tumor remains to be established. Current treatment modalities include microsurgical resection, embolization, fractionated radiotherapy, and stereotactic radiosurgery (SRS). The orbitozygomatic approach offers access to the cavernous sinus and to the frontal and middle fossa. However, one of the factors that has prevented the use of a surgical approach to cavernous sinus lesions has been the fear of causing uncontrollable bleeding. Prior to the 1980s, surgical mortality was as high as 38\% because of massive intraoperative bleeding [4]. Even with recent advances in neurosurgical techniques, complete removal of the tumor is often impossible and cranial neuropathies worsen after surgery in approximately $80 \%$ of patients. Furthermore, massive bleeding and iatrogenic injury to the sixth cranial nerve during surgery are still obstacles for these patients $[4,5]$.

Because of the high mortality and morbidity rates of surgery, radiotherapy is used as an alternative treatment method. A significant body of evidence confirms that benign tumors within the cavernous sinus, including hemangiomas, respond well to external beam radiotherapy. Accordingly, conventional fractionated radiotherapy or SRS is currently used for primary or postoperative management of hemangiomas of the cavernous sinus, with favorable results reported [5-16]. However, because cavernous sinus hemangioma is a very rare disease, only a few retrospective studies and meta-analyses have examined this tumor to date, and they have only included small numbers of cases (from 1 to 30 patients). Almost all of these studies reported outcomes after SRS, rather than after fractionated radiotherapy. Therefore, we retrospectively reviewed our institutional experience with the treatment of hemangiomas of the cavernous sinus after conventional radiotherapy.

\section{Materials and Methods}

Between January 2000 and December 2016, 65 patients were diagnosed with hemangioma of the cavernous sinus at Asan Medical Center. Among them, 29 patients were treated with radiotherapy. Nineteen patients were treated with SRS using Gamma Knife or CyberKnife systems. We retrospectively evaluated 10 patients who were treated with conventional fractionated radiotherapy. As summarized in Table 1, most patients were female $(80 \%)$ with a median age at radiotherapy of 54 years (range, 31 to 65 years). This study was approved by the Institutional Review Board of Asan Medical Center (No. 2017-0454), and the need for informed consent was waived because of the retrospective nature of the study.
Hemangiomas of the cavernous sinus were diagnosed based on their established characteristics using magnetic resonance imaging (MRI) $[13,17]$. The main symptoms and signs were headaches or symptoms related to visual disturbance and ophthalmoplegia. The characteristics of all patients enrolled in this study are listed in Table 1.

One patient had surgery and was later treated with radiotherapy for a residual mass. The other 9 patients received radiotherapy as the primary treatment modality. Radiotherapy was administered in single daily fractions of 2 Gy to a total dose of $50 \mathrm{~Gy}$ in 4 patients. The other 6 patients received a total dose of 54 Gy. The gross tumor volume (GTV) was identified as the hemangioma of the cavernous sinus itself with a planning target volume (PTV) margin of $5 \mathrm{~mm}$ in all directions.

The first follow-up was performed 1 or 3 months after treatment, and subsequent follow-ups were conducted every 1 or 2 years. A detailed questionnaire on clinical status, as well as a physical examination, was administered during each follow-up, along with brain MRI or computed tomography (CT).

All tumor responses were divided into three groups: tumor responses were defined as 'remarkable shrinkage' (tumor volume on follow-up images $<50 \%$ of the volume prior to radiotherapy), 'minimal shrinkage' (tumor volume $50 \%-75 \%$ of the tumor volume prior to radiotherapy), or 'stationary' (tumor volume 75\%-125\% of the tumor volume prior to radiotherapy). 'Tumor progression' covered all other circumstances. Tumor volumes before and after treatment were estimated by the Eclipse planning system (version 13.6; Varian Medical Systems, Palo Alto, CA, USA) based on MRI or CT. Pre- and post-radiotherapy volumes were calculated by multiplying the total reduced tumor area by the section thickness (3 $\mathrm{mm})$.

All treatment-related toxicities were scored according to the Common Terminology Criteria for Adverse Events version 4.0. Complications were adverse changes in cranial nerve function or evidence of brain parenchymal edema and/or contrast enhancement consistent with radiation-induced injury on follow-up MRI or CT.

\section{Results}

The median follow-up period for all patients was 6.8 years (range, 2.2 to 8.8 years). At the time of radiotherapy, the mean hemangioma volume was $34.1 \mathrm{~cm}^{3}$ (range, 6.8 to $83.2 \mathrm{~cm}^{3}$ ). The $\mathrm{MRI}$ or CT studies showed apparent tumor shrinkage in all cases. At the last follow-ups, MRls showed an average tumor volume 
Table 1. Summary of the characteristics of 10 patients with cavernous sinus hemangioma

\begin{tabular}{|c|c|c|c|c|c|c|c|c|c|}
\hline $\begin{array}{l}\text { Case } \\
\text { no. }\end{array}$ & $\begin{array}{l}\text { Age at RT } \\
(y r) / \text { sex }\end{array}$ & Initial presentation & $\begin{array}{l}\text { Pre-RT } \\
\text { surgery }\end{array}$ & $\begin{array}{l}\text { Initial tumor } \\
\text { volume }\left(\mathrm{cm}^{3}\right)\end{array}$ & $\begin{array}{c}\text { Volume } \\
\text { reduction rate } \\
(\%)\end{array}$ & $\begin{array}{l}\text { Dose } \\
\text { (Gy) }\end{array}$ & $\begin{array}{l}\text { Length of } \\
\text { follow-up (yr) }\end{array}$ & $\begin{array}{l}\text { Symptom } \\
\text { changes } \\
\text { post-RT }\end{array}$ & Results \\
\hline 1 & $50 / \mathrm{M}$ & Rt. ocular pain & No & 55.0 & 68.5 & 50 & 6.0 & Resolved & RS \\
\hline 2 & $65 / F$ & Headache & No & 7.2 & 51.4 & 50 & 5.7 & Resolved & RS \\
\hline 3 & $55 / F$ & $\begin{array}{l}\text { Headache } \\
\text { Decreased visual acuity }\end{array}$ & No & 83.2 & 18.9 & 54 & 8.3 & Resolved & Stationary \\
\hline 4 & $58 / F$ & $\begin{array}{l}\text { Decreased visual acuity } \\
\text { Bitemporal hemianopsia }\end{array}$ & Yes & 44.8 & 95.3 & 54 & 7.4 & Improved & RS \\
\hline 5 & $53 / F$ & Diplopia & No & 6.8 & 85.3 & 54 & 8.8 & Resolved & RS \\
\hline 6 & $39 / F$ & $\begin{array}{l}\text { Headache } \\
\text { Diplopia } \\
\text { Lt. temporal hemianopsia }\end{array}$ & No & 67.3 & 94.4 & 54 & 3.4 & Resolved & RS \\
\hline 7 & $54 / F$ & $\begin{array}{l}\text { Lt facial pain } \\
\text { Headache } \\
\text { Diplopia }\end{array}$ & No & 21.9 & 70.8 & 54 & 7.2 & $\begin{array}{l}\text { Facial pain: } \\
\text { Resolved } \\
\text { Lt visual loss }\end{array}$ & RS \\
\hline 8 & $31 / F$ & $\begin{array}{l}\text { Diplopia } \\
\text { Rt. facial pain }\end{array}$ & No & 13.9 & 86.3 & 50 & 2.2 & Resolved & RS \\
\hline 9 & $54 / F$ & Headache & No & 21.9 & 93.6 & 50 & 6.4 & Resolved & RS \\
\hline 10 & $44 / M$ & $\begin{array}{l}\text { Headache } \\
\text { diplopia }\end{array}$ & No & 18.8 & 64.9 & 54 & 8.2 & Resolved & RS \\
\hline
\end{tabular}

$\mathrm{RT}$, radiotherapy; $\mathrm{Rt}$, right; Lt., left; $\mathrm{RS}$, remarkable shrinkage.

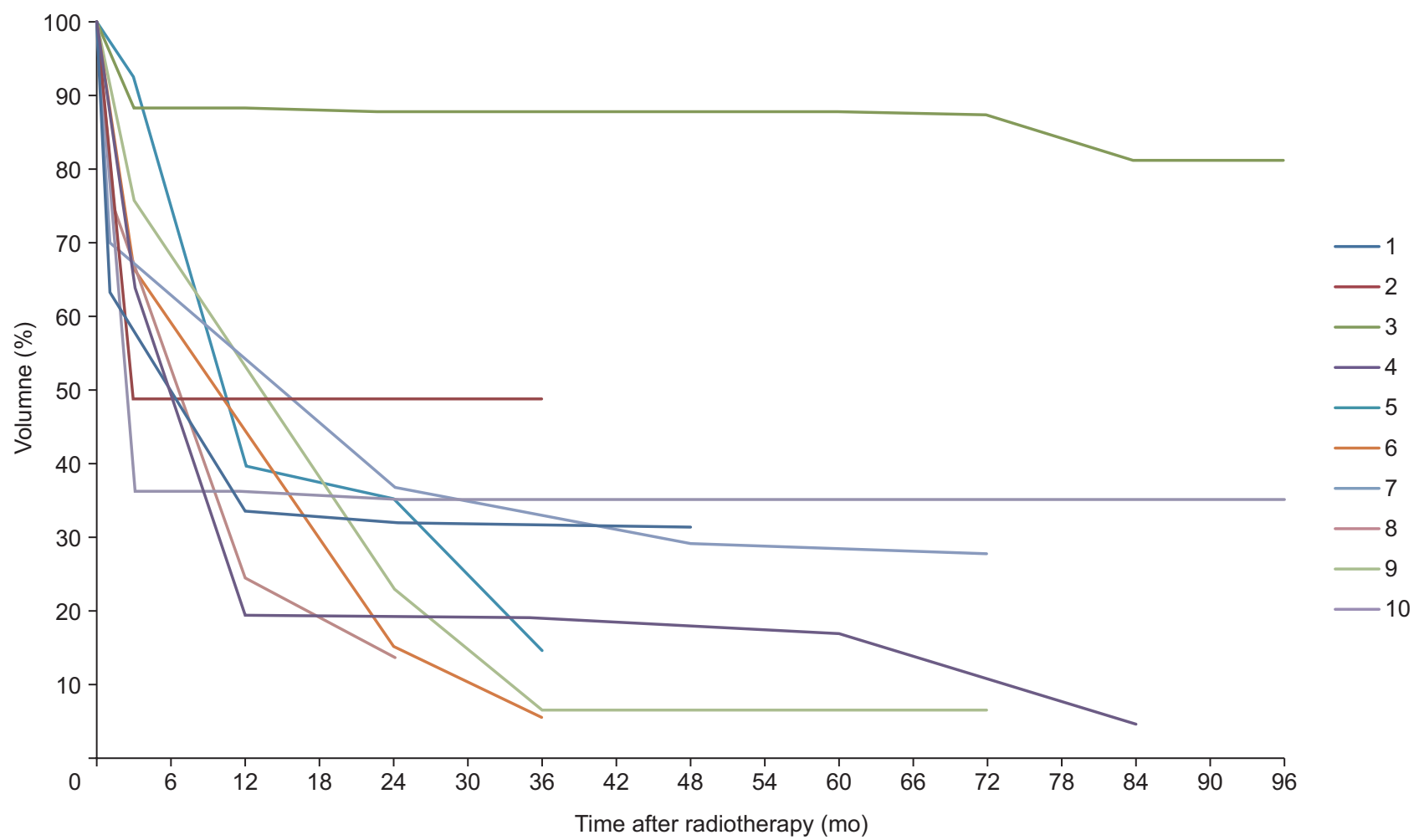

Fig. 1. Post-radiotherapy volume changes in all patients. For each patient, the figure shows the percentage of the initial tumor volume by which the tumor shrank. Results are identified by patient' number (\#1 to \#10). Almost all of the patients had early tumor shrinkage (within 3 months). The tumor volume gradually decreased over the follow-up period in all patients, without any transient volume expansion. 

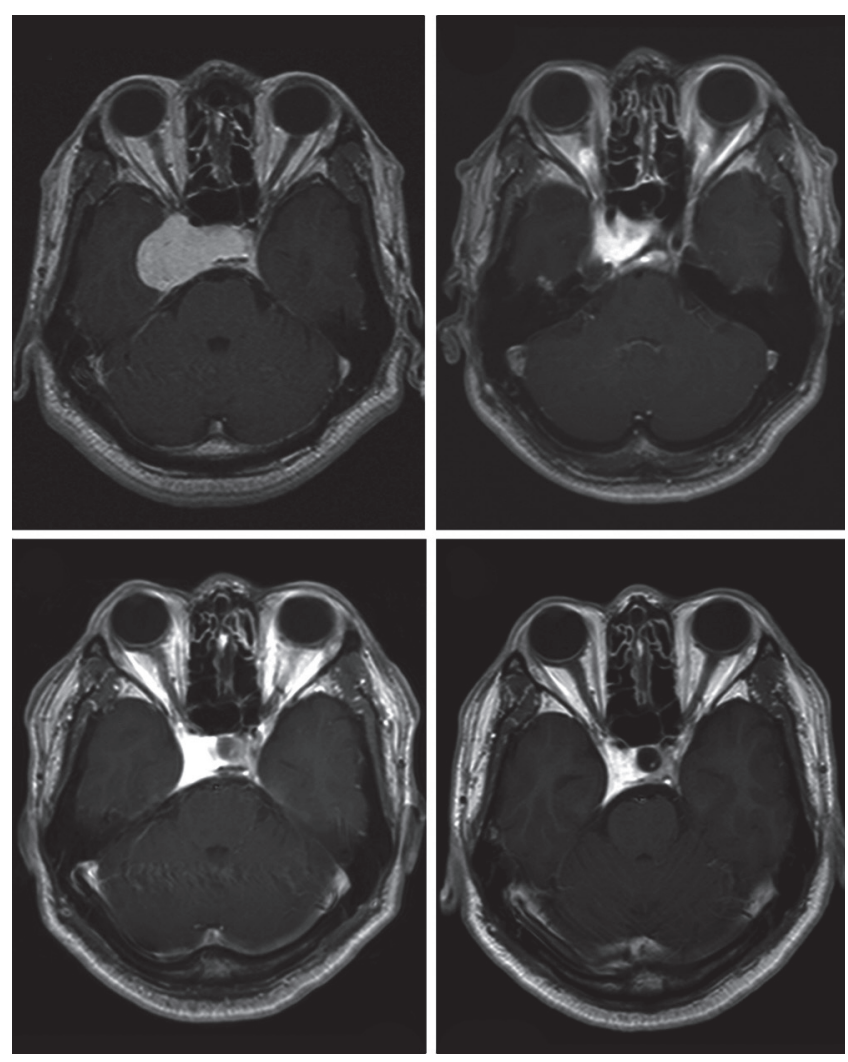

Fig. 2. Preoperative magnetic resonance imaging (MRI) identified a hemangioma in the right cavernous sinus (patient \#10). The pretreatment tumor volume was $18.8 \mathrm{~cm}^{3}$. The tumor had shrunk to $6.6 \mathrm{~cm}^{3}$ at the last follow-up. (A) Gadolinium-enhanced MRI study before radiotherapy. (B-D) Gadolinium-enhanced MRI studies at 3, 12, and 36 months after radiotherapy.

reduction rate of $72.9 \%$ (range, 18.9\% to 95.3\%). All patients except one showed remarkable shrinkage. In the remaining patient (patient \#3), the size of the mass had reduced from $83.2 \mathrm{~cm}^{3}$ to $67.5 \mathrm{~cm}^{3}$, but this amounted to only $18.9 \%$, which was considered to indicate a stationary status. Tumor responses after treatment are outlined in Table 1. The first follow-up MRIs, which were performed 1 month or 3 months after radiotherapy, showed that the tumor volume had decreased to a mean of $65.1 \%$ (range, 35.1\% to 92.6\%) of the initial volume (Fig. 1). For all patients except patient \#5, tumor size decreased dramatically within 3 months after radiotherapy. Patient \#5 showed marked tumor shrinkage at 1 year after radiotherapy. All tumor volumes gradually decreased during the follow-up period without any transient volume expansion. Further, there was no correlation between the tumor shrinkage period and tumor size. Example magnetic resonance (MR) images of one of the patients (patient \# 10 in Table 1) who obtained dramatic tumor volume shrinkage after radiotherapy are shown in Fig. 2. Before radiotherapy, an $18.8 \mathrm{~cm}^{3}$ mass (Fig. 2A) occupied the right cavernous sinus and caused diplopia and headache. At 3 months, this mass had markedly decreased in size to $6.8 \mathrm{~cm}^{3}$ (Fig. 2B). At 1 year, it had shrunk further to $6.6 \mathrm{~cm}^{3}$. Thereafter, it remained stable without any size change at the last follow-up. The patient underwent MRI every year, and Fig. $2 \mathrm{C}$ and $2 \mathrm{D}$ show MR images taken at 1 and 3 years after radiotherapy.

All of the pretreatment symptoms were improved or resolved within 3 months to 1 year. Thirty percent of the patients showed improvement and resolution of initial symptoms at the first follow-up, and the rest of the patients showed improvements and resolution within a year. At the time of the most recent follow-up examinations, all patients showed a favorable neurologic outcome of radiotherapy without deterioration, except for one patient (\#7). Changes in neurologic symptoms are listed in Table 1. Among the 9 patients with cranial nerve impairments before radiotherapy, 8 achieved complete symptomatic improvement and 1 had a partial response. One patient (\#7) complained of left facial pain, headache, and diplopia before radiotherapy, all of which had resolved at 1 month after treatment. However, she showed permanent visual acuity loss that began 1 year after the completion of radiotherapy. At that time, she noticed a sudden decrease in visual acuity and, within a week, her visual acuity deteriorated rapidly, leading to blindness.

No patient experienced a significant acute complication related to radiotherapy. The observed side effects were mild and fleeting. Grade 1 nausea and anorexia developed in one patient. Grade 2 nausea occurred in one patient during the treatment; these symptoms resolved gradually and spontaneously (without therapy) during radiotherapy.

\section{Discussion and Conclusion}

Radiotherapy is an emerging treatment for hemangioma of the cavernous sinus because of its efficacy and safety in comparison with surgery. Recently, SRS showed favorable treatment results in patients with hemangioma of the cavernous sinus $[12-14,18]$. However, when performing radiosurgery on tumors located near the optic apparatus, radiation oncologists should be concerned about toxicities, especially those like radiation-induced optic neuropathy (RION). According to previous studies, the risk of radiation-related sequelae (for example, cranial nerve palsies) might be higher if the beneficial effects of fractionation are not used $[10,19]$. The risk of RION is the primary limitation of single-fraction SRS for many patients with parasellar lesions, such as cavernous 
sinus hemangioma. As part of the Quantitative Analysis of Normal Tissue Effects in the Clinic (QUANTEC) initiative, Mayo et al. [20] reviewed the available literature to determine the dose-volume relationship of RION. For single-fraction SRS, the incidence of RION is rare for point doses less than $8 \mathrm{~Gy}$, increases between 8 to $12 \mathrm{~Gy}$, and becomes greater than 10\% at 12 to 15 Gy. Mayo et al. [20] emphasized that no study has provided adequate dose-volume information for outcome modeling. Despite the clinical usage of SRS to manage patients with cavernous sinus hemangiomas, concerns about toxicities cannot be relieved. The prescription for the peripheral dose has varied from $10.0 \mathrm{~Gy}$ to $17.0 \mathrm{~Gy}$ in several retrospective series $[13-16,18]$. Toxicity rates after SRS of $1.7 \%$ to $4 \%$ were reported in previous retrospective studies of hemangiomas of the cavernous sinus $[13,14,18]$. One meta-analysis of cavernous sinus hemangioma, which reviewed 10 retrospective studies (59 patients), reported that new cranial neuropathies developed in 1.7\% of patients [13]. Park et al. [15] reported 1 patient (4\%) who experienced transient facial numbness due to tumor enlargement after SRS. Yamamoto et al. [18] also reported hemifacial sensory disturbance in one patient (3.3\%) after SRS. Furthermore, despite the theoretically high risk of toxicities in SRS, the literature does not include any clear description of how the dose threshold for the optic apparatus has been applied [13-16,18].

Fractionated radiotherapy can be an alternative method for tumors that are adjacent to the optic apparatus, such as cavernous sinus hemangiomas. However, the clinical results of conventional radiotherapy for cavernous sinus hemangioma have only been reported for 8 patients, in total $[6-8,11]$. All of the relevant studies were case reports, and only 2 of the reported patients were treated with definitive fractionated radiotherapy. Three of the 8 patients received radiotherapy postoperatively ( 2 after subtotal resection, and 1 for recurrence case after 2 surgeries). The radiation dose also varied from 30 Gy to $50 \mathrm{~Gy}$. Shibata and Mori [6] reported the case of a patient who underwent subtotal resection followed by $50 \mathrm{~Gy}$ of fractionated radiotherapy. The tumor significantly reduced in size and neurologic symptoms improved. However, the patient underwent a second operation and died as a result of surgical complications. The other 2 patients reported by Shibata and Mori [6] showed improvements in neurologic symptoms and significant tumor reduction after $30 \mathrm{~Gy}$ of radiotherapy without radiotherapy-related toxicities. Yamamoto et al. [8] reported the case of a patient with hemangioma of the cavernous sinus who achieved symptom improvements and a significantly reduced tumor size after
50 Gy of irradiation without any toxicity. Rigamonti et al. [7] reported three cases of hemangioma of the cavernous sinus that were treated with fractionated radiotherapy. Only one patient received 50 Gy of fractionated definitive radiotherapy. The size of the patient's tumor decreased significantly, but the neurologic symptoms were clinically unchanged. The other 2 patients received 50 Gy of radiotherapy after subtotal resection and then underwent a second total resection. The patients showed dramatic reductions in tumor size, but still had neurologic symptoms after the second surgery. Thus, there are few clinical data on definitive fractionated radiotherapy. In particular, data on complications are not available.

Here, we report our institutional experience with definitive fractionated radiotherapy for hemangioma of the cavernous sinus. Our study showed a tumor volume reduction of $72.9 \%$ (range, 18.9\% to 95.3\%). Long-term follow-up showed that the size of the tumor decreased rapidly within 3 months to 1 year after the end of treatment, and thereafter decreased gradually. All patients with cranial nerve impairments showed complete resolution or improvement except for one patient (\#7) who experienced visual acuity loss 1 year after treatment. We cannot rule out the possibility of side effects related to radiotherapy, even though the optic apparatus was exposed to less than $50 \mathrm{~Gy}$ of the prescribed $D_{\max }$ and the risk of neuropathy after conventional radiotherapy is usually very low. In addition, the patient experienced acute onset of blindness, while the side effects of conventional radiotherapy are characterized by gradual visual loss over several months. Therefore, this patient's blindness should be regarded as neuropathy due to persistent nerve compression, and the probability of RION is thought to be low.

The QUANTEC initiative reported expected risks of RION of 3\%, 3\%-7\%, and 7\%-20\% with maximum doses to the optic nerves of $<50 \mathrm{~Gy}, 55-60 \mathrm{~Gy}$, and $>60 \mathrm{~Gy}$, respectively $[20,21]$. In the current study, the prescribed radiation dose was 50-54 Gy and the treatment plan did not exceed 50 Gy of $D_{\max }$ to the optic apparatus. This treatment policy is slightly more conservative than the QUANTEC recommendations. Particular attention should be paid to the treatment of tumors, especially near the optic apparatus, because RION is a serious complication when it occurs. By using fractionated radiotherapy, we were able to treat patients relatively safely and achieve good therapeutic results.

This study suggests that definitive fractionated radiotherapy can be applied with relative safety in patients with hemangiomas of the cavernous sinus. Fractionated radiotherapy may be preferred by those who are concerned 
about toxicity, despite the rare reports of complications and the disadvantages of longer treatment periods.

In conclusion, our institutional experience substantiates the role of fractionated radiotherapy in treating hemangiomas of the cavernous sinus. Fractionated radiotherapy appears to be an effective and relatively safe treatment modality for the management of hemangiomas of the cavernous sinus and could be used as the primary treatment.

\section{Conflict of Interest}

No potential conflict of interest relevant to this article was reported.

\section{References}

1. George A, Mani V, Noufal A. Update on the classification of hemangioma. J Oral Maxillofac Pathol 2014;18(Suppl 1):S11720.

2. Chou $\mathrm{CW}$, Wu HM, Huang $\mathrm{Cl}$, et al. Gamma knife surgery for cavernous hemangiomas in the cavernous sinus. Neurosurgery 2010;67:611-6.

3. Gonzalez LF, Lekovic GP, Eschbacher J, Coons S, Porter RW, Spetzler RF. Are cavernous sinus hemangiomas and cavernous malformations different entities? Neurosurg Focus 2006;21:e6.

4. Linskey ME, Sekhar LN. Cavernous sinus hemangiomas: a series, a review, and an hypothesis. Neurosurgery 1992;30:101-8.

5. Seo Y, Fukuoka S, Sasaki T, Takanashi M, Hojo A, Nakamura $H$. Cavernous sinus hemangioma treated with gamma knife radiosurgery: usefulness of SPECT for diagnosis: case report. Neurol Med Chir (Tokyo) 2000;40:575-80.

6. Shibata S, Mori K. Effect of radiation therapy on extracerebral cavernous hemangioma in the middle fossa: report of three cases. J Neurosurg 1987;67:919-22.

7. Rigamonti D, Pappas CT, Spetzler RF, Johnson PC. Extracerebral cavernous angiomas of the middle fossa. Neurosurgery 1990;27:306-10.

8. Yamamoto $Y$, Weining $Z$, Ohashi T. Intracavernous cavernous hemangioma: dynamic CT findings and effectiveness of irradiation: case report. Neurol Med Chir (Tokyo) 1992;32:93-5.
9. Jamjoom AB. Response of cavernous sinus hemangioma to radiotherapy: a case report. Neurosurg Rev 1996;19:261-4.

10. Kuo JS, Chen JC, Yu C, et al. Gamma knife radiosurgery for benign cavernous sinus tumors: quantitative analysis of treatment outcomes. Neurosurgery 2004;54:1385-94.

11. Grosu AL, Nieder C. Stereotactic fractionated radiotherapy for recurrent capillary hemangioma of the cavernous sinus. Strahlenther Onkol 2006;182:179-82.

12. Wang X, Liu X, Mei G, Dai J, Pan L, Wang E. Phase II study to assess the efficacy of hypofractionated stereotactic radiotherapy in patients with large cavernous sinus hemangiomas. Int J Radiat Oncol Biol Phys 2012;83:e223-30.

13. Wang X, Mei G, Liu X, Dai J, Pan L, Wang E. The role of stereotactic radiosurgery in cavernous sinus hemangiomas: a systematic review and meta-analysis. J Neurooncol 2012;107:239-45.

14. Song SW, Kim DG, Chung HT, et al. Stereotactic radiosurgery for cavernous sinus hemangiomas. J Neurooncol 2014;118:163-8.

15. Park CK, Choi SK, Kang IH, Choi MK, Park BJ, Lim YJ. Radiosurgical considerations for cavernous sinus hemangioma: long-term clinical outcomes. Acta Neurochir (Wien) 2016;158:313-8.

16. Xu O, Shen J, Feng Y, Zhan R. Gamma Knife radiosurgery for the treatment of cavernous sinus hemangiomas. Oncol Lett 2016;11:1545-8.

17. Anqi $X$, Zhang $S$, Jiahe $X$, Chao $Y$. Cavernous sinus cavernous hemangioma: imaging features and therapeutic effect of Gamma Knife radiosurgery. Clin Neurol Neurosurg 2014;127:59-64.

18. Yamamoto M, Kida Y, Fukuoka S, et al. Gamma Knife radiosurgery for hemangiomas of the cavernous sinus: a seven-institute study in Japan. J Neurosurg 2010;112:772-9.

19. Levegrun S, Hof H, Essig M, Schlegel W, Debus J. Radiationinduced changes of brain tissue after radiosurgery in patients with arteriovenous malformations: dose/volume-response relations. Strahlenther Onkol 2004;180:758-67.

20. Mayo C, Martel MK, Marks LB, Flickinger J, Nam J, Kirkpatrick J. Radiation dose-volume effects of optic nerves and chiasm. Int J Radiat Oncol Biol Phys 2010;76(3 Suppl):S28-35.

21. Emami B, Lyman J, Brown $A$, et al. Tolerance of normal tissue to therapeutic irradiation. Int J Radiat Oncol Biol Phys $1991 ; 21: 109-22$. 